\title{
Norovirus recognition sites on histo-blood group antigens
}

\author{
Haruko Shirato* \\ Department of Virology II, National Institute of Infectious Diseases, Musashi-Murayama, Tokyo, Japan \\ *Correspondence: harukos@nih.go.jp
}

Norovirus (NoV) is the major causative agent of acute viral gastroenteritis worldwide. Based on genetic analyses, human NoV strains have been classified into at least three genogroups: genogroup I (GI), GII, and GIV, which contain at least 15, 18, and 1 genotypes, respectively (Kageyama et al., 2004). Notably, these NoV genotypes are morphologically similar to one another but differ antigenically (Kapikian, 1996; Estes et al., 1997; Hansman et al., 2006). Since no cell culture system has been developed yet, molecular analyses to elucidate the mechanisms underlying infection or productive replication have been stalled until recently. The primary NoV replication site in humans is unknown, but intestinal biopsy from volunteer who became ill following oral administration of NoV exhibited histopathologic lesions, in which the villi of the proximal small intestine were blunted (Agus et al., 1973). More than 30 years ago, the initial NoV challenge studies conducted in volunteers found that a subset of individuals was repeatedly susceptible to NoV infection, whereas a second subset was repeatedly resistant to infection (Parrino et al., 1977). A genetic factor, possibly a receptor, was hypothesized to affect the susceptibility of an individual to NoV infection. Recently, a mechanism that explains the susceptibility or resistance to $\mathrm{NoV}$ infection has been identified; namely, NoV attaches to histo-blood group antigens (HBGAs) on potential host cells in the gut (Lindesmith et al., 2003).

HBGAs are structurally related oligosaccharides that include $\mathrm{ABH}$ antigens and Lewis (Le) antigens (Figure 1). Polymorphisms in the $\mathrm{ABH}$ antigens are induced by variations in the core structure. Type 1 chain $\mathrm{ABH}$ antigens are widely expressed in endodermally derived tissues such as the lining epithelia and the glandular epithelia (Oriol et al., 1986). Meanwhile, type 2 chain $\mathrm{ABH}$ antigens are found pri-

Abbreviations: Fuc, fucose; Gal, galactose; GalNAc, $\mathrm{N}$-acetylgalactosamine; Glc, glucose; GlcNAc, $\mathrm{N}$-acetylglucosamine; HBGA, histo-blood group antigen; NoV, norovirus; VP, virion protein. marily in ecto- or meso-dermally derived tissues, including skin and erythrocytes (Hakomori, 1981; Dabelsteen et al., 1982; Oriol et al., 1986). In the human gastroduodenal junction, type 1 structures are found exclusively at the level of the surface epithelia, whereas type 2 structures are preferentially found at the glandular level (Mollicone et al., 1985).

Details of the NoV recognition of HBGAs were clarified with in vitro experiments, enzyme-linked immunosorbent assays (ELISAs), and surface plasmon resonance (SPR) experiments using virus-like particles (VLPs), as well as crystallization studies using $\mathrm{P}$ domains. When the $\mathrm{NoV}$ VP1 gene, which encodes a capsid protein, is expressed in insect cells, capsid proteins of approximately $58 \mathrm{kDa}$ are generated and self-assembled into VLPs (Xi et al., 1990; Jiang et al., 1993). Though artificial, these VLPs are morphologically and antigenically similar to those of the respective native virions (Jiang et al., 1992; Green et al., 1993; Prasad et al., 1994, 1999). VP1 has two major domains: a shell (S) domain, which forms the core of the icosahedral shell (Bertolotti-Ciarlet et al., 2002), and a protruding $(\mathrm{P})$ domain, which forms arches extending from the shell and is responsible for host interactions (Tan et al., 2004, 2011; Tan and Jiang, 2005a,b, 2007). The association and dissociation kinetics for NoVVLPs binding to HBGAs were measured with SPR experiments (Choi et al., 2008; Shirato et al., 2008), which allowed us to visualize

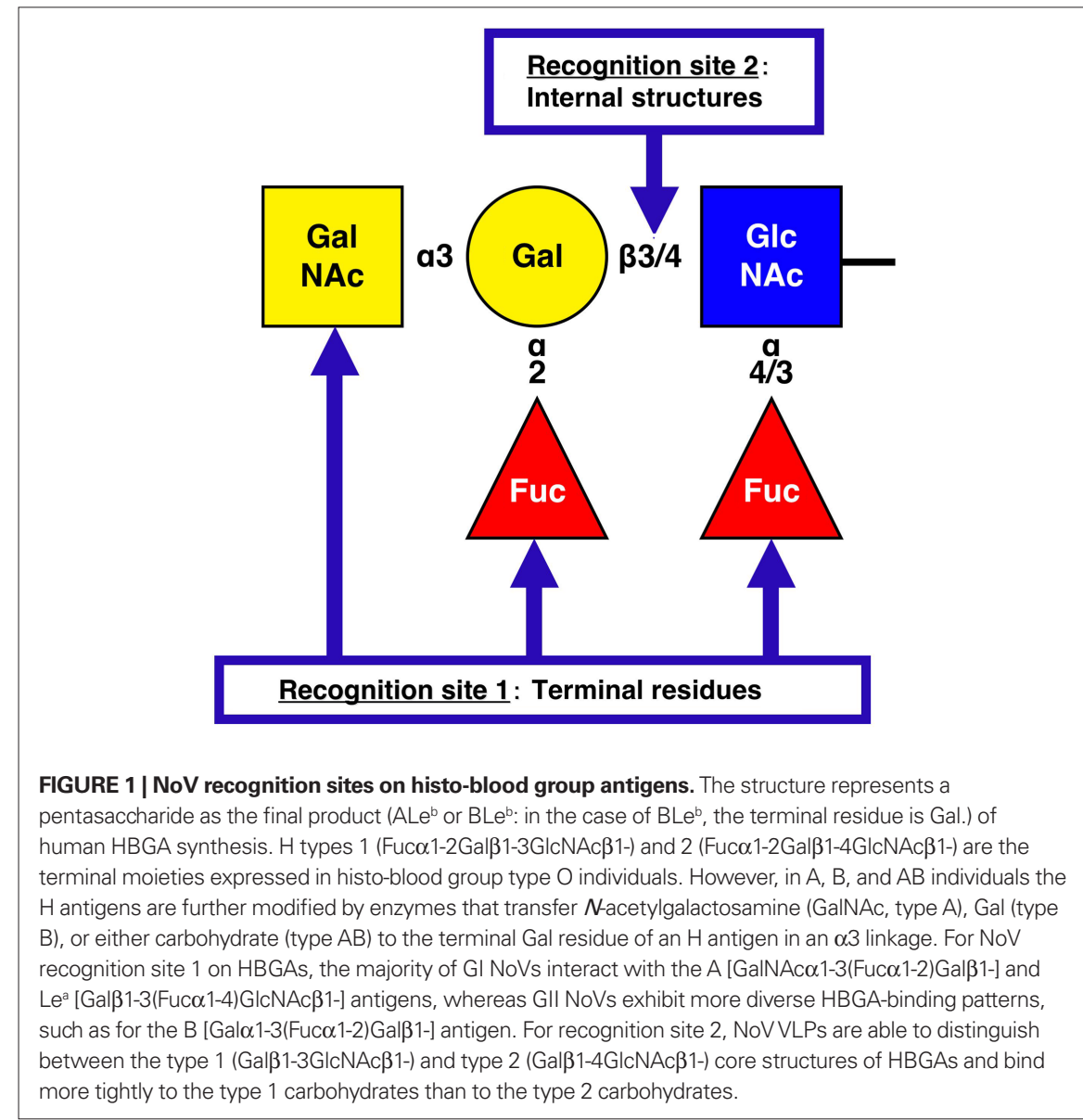


each binding step in about a 120-1200 s reaction time, whereas ELISA allowed us to visualize the last step in a total reaction time of about 8 h. Recent crystallographic studies have revealed that the $\mathrm{P}$ domain dimers form a structure similar to that of the corresponding region of the VP1 protein, indicating that the $\mathrm{P}$ domain proteins are valid alternatives for HBGA-binding studies (Choi et al., 2008). Moreover, the $\mathrm{P}$ domain proteins have an advantage over VLPs in structural studies, because they are easily purified from extracts of transformed E. coli cells. The crystallization studies have identified not only the recognition sites on HBGAs by No V but also the putative binding sites on the NoV capsid protein. These in vitro studies clarified that the binding properties of human NoV to HBGAs were variable and that the terminal residues and internal structures were important in the NoV-HBGA interactions (Harrington et al., 2002, 2004; Huang et al., 2003, 2005; Shirato-Horikoshi et al., 2007; Shirato et al., 2008).

To date, the interactions between carbohydrates and 29 NoV VLPs, including 10 GI and 19 GII VLPs, have been reported. Figure 1 illustrates the recognition sites on HBGAs by NoV. For recognition site 1, several binding patterns have been identified according to the interaction with the $\mathrm{H}(\alpha 2 \mathrm{Fuc}), \mathrm{A}(\alpha \mathrm{GalNAc}), \mathrm{B}(\alpha \mathrm{Gal})$, and Le ( $\alpha 4$ Fuc) epitopes (Huang et al., 2005; Shirato et al., 2008). The binding of NoVs to these terminal residues is genogroup dependent. The majority of GI NoVs interact with the A and $\mathrm{Le}^{\mathrm{a}}$ antigens (Hutson et al., 2003; Shirato et al., 2008), whereas GII NoVs exhibit more diverse HBGA-binding patterns, such as in the binding of the $\mathrm{B}$ antigen (Harrington et al., 2004; Huang et al., 2005; Cao et al., 2007; Shirato et al., 2008). Indeed, strains of the same genogroup tend to have identical amino acids on the putative binding sites. Moreover, structural studies revealed that the carbohydrate-binding site in the $\mathrm{P}$ domain is distinctly different between the GI and GII genogroups both in terms of its location and its structural characteristics (Cao et al., 2007; Choi et al., 2008), despite the VP1 protein sharing a similar $\mathrm{S}$ and $\mathrm{P}$ domain organization and polypeptide fold between these two genogroups. However, one group has argued that the specificity for HBGA is strain-dependent across GI and GII (Huang et al., 2005). These authors concluded that NoV-HBGA-binding patterns could be classified into two groups, an A/B-binding group and a Le-binding group, and that no correlation was present between the binding patterns and the genogroup. However, a single amino acid change in the $\mathrm{P}$ domain was found to result in a change in the pattern of HBGA binding (Tan et al., 2003), so that reaching conclusions is difficult. For recognition site 2, both GI and GII NoV VLPs are able to distinguish the difference between type 1 and type 2 carbohydrates. In SPR experiments, GI and GII NoV VLPs more efficiently bound to type 2 than type 1 for the $\mathrm{H}, \mathrm{A}$ and $\mathrm{B}$ antigens (Shirato et al., 2008). Moreover, the dissociation of GII NoV VLP from the B type 1 antigen was slower than that from the B type 2 antigen (Shirato et al., 2008). ELISA experiments also showed that the NoV VLPs were able to distinguish the difference between the core structures of HBGAs. The GIVLP has been reported to bind synthetic H carbohydrates in the following order of strength: H type 1 trisaccharides, $H$ type 2 trisaccharides, and $\mathrm{H}$ disaccharides (Hutson et al., 2003). The binding of GII NoV VLP to B type 1 has been reported to be stronger than that to B type 2 (Shirato et al., 2008). In addition, immunohistochemical analysis has revealed that the binding of GI to the gastroduodenal junction correlated with the presence of $\mathrm{H}$ type 1 antigen but not to $\mathrm{H}$ type 2 antigen (Marionneau et al., 2002). These studies indicate that the NoV VLPs are able to distinguish between type 1 and type 2 core structures of HBGAs and to bind more tightly to the type 1 carbohydrates than to the type 2 carbohydrates.

Avian and equine influenza viruses are known to preferentially bind to the terminal sialic acid $\alpha 2-3 \mathrm{Gal}(\mathrm{SA} \alpha 2-3 \mathrm{Gal})$ linkage, whereas human influenza viruses preferentially bind to the SA $\alpha 2-6 \mathrm{Gal}$ linkage (Rogers and Paulson, 1983; Rogers et al., 1983; Connor et al., 1994), affording a major impact on the host specificity of these influenza viruses. A similar relationship may exist between NoV carbohydrate recognition and the tissue specificity of this virus, since the binding of NoV to the gastroduodenal junction has been reported to correlate with the presence of the $\mathrm{H}$ type 1 but not the $\mathrm{H}$ type 2 antigen, as described above (Marionneau et al., 2002). In conclusion, HBGAs are important factors in determining the host specificity of NoV, although it remains unclear whether they function as the primary receptor or enhance $\mathrm{NoV}$ infectivity and/or attachment to a common cellular receptor. Since NoV comprises a number of antigenically diverse groups, identification of the common NoV-binding epitopes on host cells, if any, should be useful in the development of possible antiviral agents.

\section{ACKNOWLEDGMENT}

This work was supported by the R\&D Project of Industrial Science and Technology Frontier Program, which is supported by the New Energy and Industrial Technology Development Organization.

\section{REFERENCES}

Agus, S. G., Dolin, R., Wyatt, R. G., Tousimis, A. J., and Northrup, R.S. (1973). Acute infectious nonbacterial gastroenteritis: intestinal histopathology. Histologic and enzymatic alterations during illness produced by the Norwalk agent in man. Ann. Intern. Med. 79, 18-25.

Bertolotti-Ciarlet, A., White, L. J., Chen, R., Prasad, B. V., and Estes, M. K. (2002). Structural requirements for the assembly of Norwalk virus-like particles. J. Virol. 76, 4044-4055.

Cao, S., Lou, Z., Tan, M., Chen, Y., Liu, Y., Zhang, Z., Zhang, X. C., Jiang, X., Li, X., and Rao, Z. (2007). Structural basis for the recognition of blood group trisaccharides by norovirus. J. Virol. 81, 5949-5957.

Choi, J. M., Hutson, A. M., Estes, M. K., and Prasad, B. V. (2008). Atomic resolution structural characterization of recognition of histo-blood group antigens by Norwalk virus. Proc. Natl. Acad. Sci. U.S.A. 105, 9175-9180.

Connor, R. J., Kawaoka, Y., Webster, R. G., and Paulson, J. C. (1994). Receptor specificity in human, avian, and equine $\mathrm{H} 2$ and $\mathrm{H} 3$ influenza virus isolates. Virology 205, 17-23.

Dabelsteen, E., Vedtofte, P., Hakomori, S. I., and Young, W.W. (1982). Carbohydrate chains specific for blood group antigens in differentiation of human oral epithelium. J. Invest. Dermatol. 79, 3-7.

Estes, M. K., Ball, J. M., Crawford, S. E., O’Neal, C., Opekun, A. A., Graham, D. Y., and Conner, M. E. (1997). Virus-like particle vaccines for mucosal immunization. Adv. Exp. Med. Biol. 412, 387-395.

Green, K. Y., Lew, J. F., Jiang, X., Kapikian, A. Z., and Estes, M. K. (1993). Comparison of the reactivities of baculovirus-expressed recombinant Norwalk virus capsid antigen with those of the native Norwalk virus antigen in serologic assays and some epidemiologic observations. J. Clin. Microbiol. 31, 2185-2191.

Hakomori, S. (1981). Blood group ABH and Ii antigens of human erythrocytes: chemistry, polymorphism, and their developmental change. Semin. Hematol. 18, 39-62.

Hansman, G. S., Natori, K., Shirato-Horikoshi, H., Ogawa, S., Oka, T., Katayama, K., Tanaka, T., Miyoshi, T., Sakae, K., Kobayashi, S., Shinohara, M., Uchida, K., Sakurai, N., Shinozaki, K., Okada, M., Seto, Y., Kamata, K., Nagata, N., Tanaka, K., Miyamura, T., and Takeda, 
N. (2006). Genetic and antigenic diversity among noroviruses. J. Gen. Virol. 87, 909-919.

Harrington, P. R., Lindesmith, L., Yount, B., Moe, C. L., and Baric, R. S. (2002). Binding of Norwalk viruslike particles to $\mathrm{ABH}$ histo-blood group antigens is blocked by antisera from infected human volunteers or experimentally vaccinated mice. J. Virol. 76, 12335-12343.

Harrington, P. R., Vinje, J., Moe, C. L., and Baric, R. S. (2004). Norovirus capture with histo-blood group antigens reveals novel virus-ligand interactions. $J$. Virol. 78, 3035-3045.

Huang, P., Farkas, T., Marionneau, S., Zhong, W., RuvoenClouet, N., Morrow, A. L., Altaye, M., Pickering, L. K., Newburg, D. S., Lependu, J., and Jiang, X. (2003). Noroviruses bind to human $\mathrm{ABO}$, Lewis, and secretor histo-blood group antigens: identification of 4 distinct strain-specific patterns. J. Infect. Dis. 188, 19-31.

Huang, P., Farkas, T., Zhong, W., Tan, M., Thornton, S., Morrow, A. L., and Jiang, X. (2005). Norovirus and histo-blood group antigens: demonstration of a wide spectrum of strain specificities and classification of two major binding groups among multiple binding patterns. J. Virol. 79, 6714-6722.

Hutson, A. M., Atmar, R. L., Marcus, D. M., and Estes, M. K. (2003). Norwalk virus-like particle hemagglutination by binding to $\mathrm{h}$ histo-blood group antigens. J. Virol. 77, 405-415.

Jiang, X., Wang, M., Graham, D. Y., and Estes, M. K. (1992). Expression, self-assembly, and antigenicity of the Norwalk virus capsid protein. J. Virol. 66, 6527-6532.

Jiang, X., Wang, M., Wang, K., and Estes, M. K. (1993). Sequence and genomic organization of Norwalk virus. Virology 195, 51-61.

Kageyama, T., Shinohara, M., Uchida, K., Fukushi, S., Hoshino, F. B., Kojima, S., Takai, R., Oka, T., Takeda, N., and Katayama, K. (2004). Coexistence of multiple genotypes, including newly identified genotypes, in outbreaks of gastroenteritis due to Norovirus in Japan. J. Clin. Microbiol. 42, 2988-2995.

Kapikian, A. Z. (1996). Overview of viral gastroenteritis. Arch. Virol. Suppl. 12, 7-19.
Lindesmith, L., Moe, C., Marionneau, S., Ruvoen, N., Jiang, X., Lindblad, L., Stewart, P., Lependu, J., and Baric, R. (2003). Human susceptibility and resistance to Norwalk virus infection. Nat. Med. 9, 548-553.

Marionneau, S., Ruvoen, N., Le Moullac-Vaidye, B., Clement, M., Cailleau-Thomas, A., Ruiz-Palacois, G., Huang, P., Jiang, X., and Le Pendu, J. (2002). Norwalk virus binds to histo-blood group antigens present on gastroduodenal epithelial cells of secretor individuals. Gastroenterology 122, 1967-1977.

Mollicone, R., Bara, J., Le Pendu, J., and Oriol, R. (1985). Immunohistologic pattern of type 1 (Lea, Leb) and type $2(\mathrm{X}, \mathrm{Y}, \mathrm{H})$ blood group-related antigens in the human pyloric and duodenal mucosae. Lab. Invest. 53, 219-227.

Oriol, R., Le Pendu, J., and Mollicone, R. (1986). Genetics of ABO, H, Lewis, $\mathrm{X}$ and related antigens. Vox Sang. 51, 161-171.

Parrino, T. A., Schreiber, D. S., Trier, J. S., Kapikian, A. Z., and Blacklow, N. R. (1977). Clinical immunity in acute gastroenteritis caused by Norwalk agent. N. Engl. J. Med. 297, 86-89.

Prasad, B. V., Hardy, M. E., Dokland, T., Bella, J., Rossmann, M. G., and Estes, M. K. (1999). X-ray crystallographic structure of the Norwalk virus capsid. Science 286, 287-290.

Prasad, B. V., Rothnagel, R., Jiang, X., and Estes, M. K. (1994). Three-dimensional structure of baculovirusexpressed Norwalk virus capsids. J. Virol. 68, 5117-5125.

Rogers, G. N., and Paulson, J. C. (1983). Receptor determinants of human and animal influenza virus isolates: differences in receptor specificity of the $\mathrm{H} 3$ hemagglutinin based on species of origin. Virology 127,361-373.

Rogers, G. N., Pritchett, T. J., Lane, J. L., and Paulson, J. C. (1983). Differential sensitivity of human, avian, and equine influenza $A$ viruses to a glycoprotein inhibitor of infection: selection of receptor specific variants. Virology 131, 394-408.

Shirato, H., Ogawa, S., Ito, H., Sato, T., Kameyama, A., Narimatsu, H., Xiaofan, Z., Miyamura, T., Wakita, T., Ishii, K., and Takeda, N. (2008). Noroviruses distinguish between type 1 and type 2 histo-blood group antigens for binding. J. Virol. 82, 10756-10767.
Shirato-Horikoshi, H., Ogawa, S., Wakita, T., Takeda, N., and Hansman, G. S. (2007). Binding activity of norovirus and sapovirus to histo-blood group antigens. Arch. Virol. 152, 457-461.

Tan, M., Fang, P. A., Xia, M., Chachiyo, T., Jiang, W., and Jiang, X. (2011). Terminal modifications of norovirus $P$ domain resulted in a new type of subviral particles, the small P particles. Virology 410, 345-352.

Tan, M., Hegde, R. S., and Jiang, X. (2004). The P domain of norovirus capsid protein forms dimer and binds to histo-blood group antigen receptors. J. Virol. 78, 6233-6242.

Tan, M., Huang, P., Meller, J., Zhong, W., Farkas, T., and Jiang, X. (2003). Mutations within the P2 domain of norovirus capsid affect binding to human histo-blood group antigens: evidence for a binding pocket. J. Virol. 77, 12562-12571.

Tan, M., and Jiang, X. (2005a). Norovirus and its histoblood group antigen receptors: an answer to a historical puzzle. Trends Microbiol. 13, 285-293.

Tan, M., and Jiang, X. (2005b). The p domain of norovirus capsid protein forms a subviral particle that binds to histo-blood group antigen receptors. J. Virol. 79, 14017-14030.

Tan, M., and Jiang, X. (2007). Norovirus-host interaction: implications for disease control and prevention. Expert Rev. Mol. Med. 9, 1-22.

Xi, J. N., Graham, D. Y., Wang, K. N., and Estes, M. K. (1990). Norwalk virus genome cloning and characterization. Science 250, 1580-1583.

Received: 23 April 2012; accepted: 23 April 2012; published online: 17 May 2012.

Citation: Shirato H (2012) Norovirus recognition sites on histo-blood group antigens. Front. Microbio. 3:177. doi: 10.3389/fmicb.2012.00177

This article was submitted to Frontiers in Virology, a specialty of Frontiers in Microbiology.

Copyright $\odot 2012$ Shirato. This is an open-access article distributed under the terms of the Creative Commons Attribution Non Commercial License, which permits noncommercial use, distribution, and reproduction in other forums, provided the original authors and source are credited. 